\title{
4 The Iconography of Time: What the Visualisation of Efficacious Movement (Shi 勢) Tells Us about the Composition of the Yijin Jing 易筋經 (Canon for Supple Sinews)
}

\section{Elisabeth $\mathrm{Hsu}^{*}$}

\section{Introduction}

Time can be comprehended cyclically, as we do when we think of diurnal or seasonal cycles. Or it can be experienced in a polar way, as when we contrast day and night as opposites of light and dark, or as the ancient Chinese did, when they spoke of 'spring and autumn' - chunqiu 春秋-as polar Yin and Yang 陰陽 alternations between periods of expansive growth (zhang 張) and contraction (shou 收). As argued elsewhere, the bodily routines in the Yijinjing 易筋經 (Canon for Supple Sinews, also called The Sinews Transformation Classic) lead the practitioner to embody this latter experience of time as a pulsating movement of Yin Yang directional opposition. ${ }^{1}$
This chapter will discuss another common way of relating to time, namely time as a linear flow visually rendered as a vector. In the contemporary West, the vector goes from the past on the left-hand side to the future on the right. This embodied experience, like that of writing from the left to the right on a sheet of paper, may well explain its directionality. Time as linear trajectory is not particular to the West, however. It also underlies, for instance, the Tibetan medical depiction of different pulse qualities in an educative thanka of the Blue Beryl from the 17 th century. $^{2}$ Pulse qualities are shown there as curves along a vector (Fig. 1), much as pulse beats or heart beats in a biomedical ECG are visualised as sinuses along a horizontal timeline. Yet the timeline for pulse movements on this Tibetan thanka is vertical. ${ }^{3}$

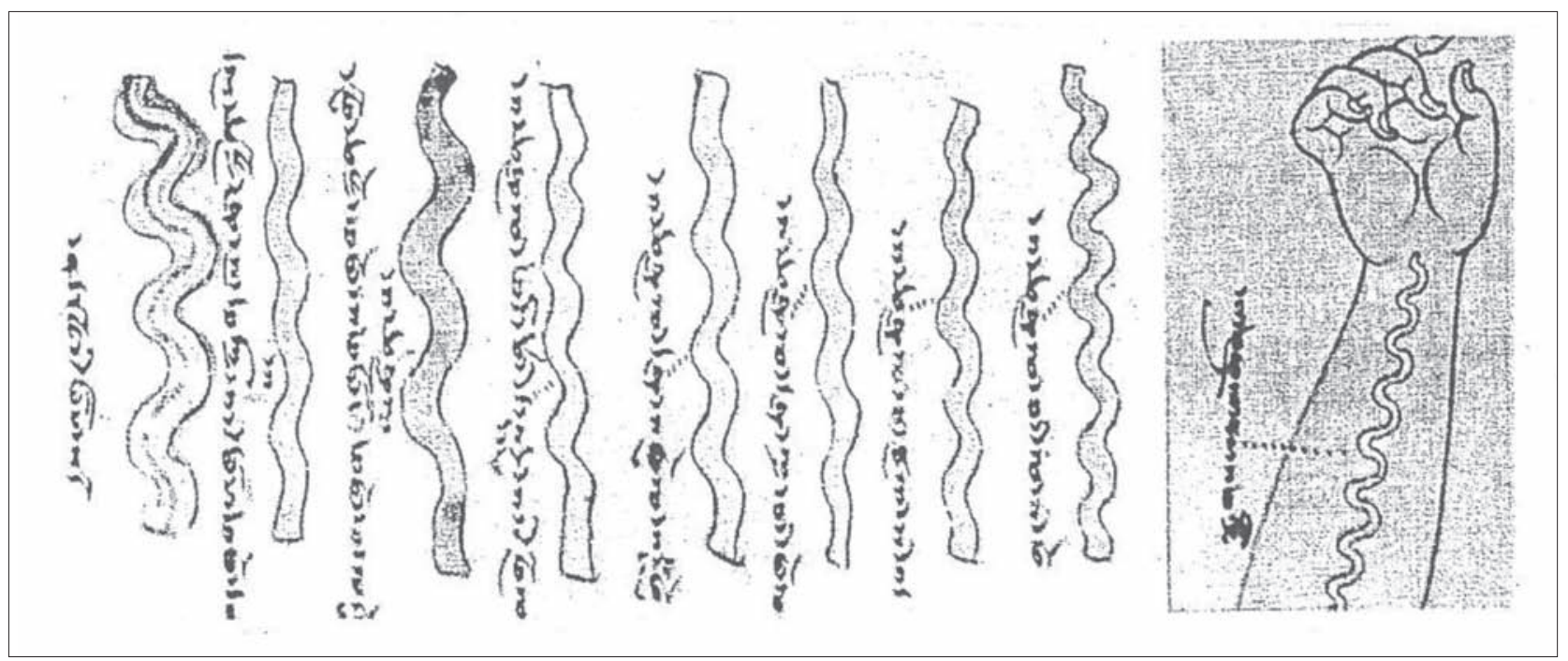

Figure 4.1 Depiction of Tibetan pulses along a linear trajectory of time (Parfionovitch et al. 1992, pl. 6o, line 4)

* I am much indebted to Master Qiu and Lim Chee Han for teaching me the postures/movements they practised of the Yijin jing. Thanks go also to Meir Shahar for making substantial inroads into its textual history (particularly after I expressed this wish at the conference on 'Chinese Medicine: A Visual History', in Beijing, 14-17 September, 2005). Finally, I thank the reviewers and editing team that made this publication possible.

1 Secondary literature on the Yijin jing in western languages is to date inexistent, with the notable exceptions of Shahar (2008, pp. 160-73) and Kohn (2008, pp. 195-7). This article is part of a trilogy, all of which compare text with practice: Hsu and Lim (2016) compare a Singaporean version of the Yijin jing with one in the People's Republic of China, and Hsu (in prep.) addresses methodological questions of historiography. 


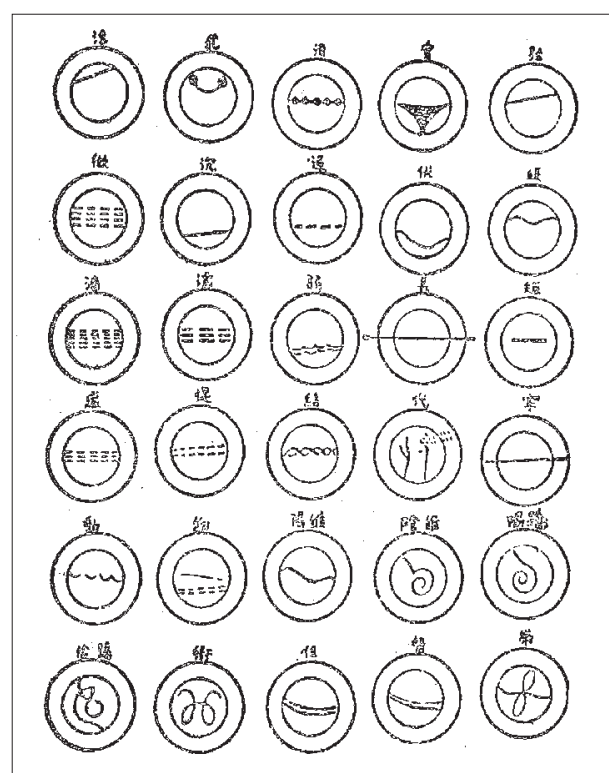

Figure 4.2 Depiction of Chinese mai 脈 in an iconic-indexical manner. (Ma Kanwen 1983, p. 64 claims that he found these images in an Arabic treatise, which the author could not locate; they are reproduced here in the hope that a reader may identify them.)

Another iconography of time seems to have prevailed when visualising Chinese medical 'pulse images' (mai xiang 脉象), ${ }^{4}$ where each pulse image would be depicted in a round medallion (Fig. 2). Furthermore, as a detailed study of the vessel-pulses mai 脈/脉 in a text of the received tradition suggests, ${ }^{5}$ mai were comprehended as both 'iconic' and 'indexical' signs (in C.S. Peirce's terms). For instance, an 'intense' mai (jimai 急脈), in contrast to a 'slack' mai (huan mai 緩脈), would be indexical of intense urges to urinate, and of intense pain, just as smoke is indexical of fire. Simultaneously, an 'intense' pulse had an iconic resemblance to the tensed-up tendons or muscles in those situations. ${ }^{6}$ Evidently, the movement of the mai was assessed not only visually in medallions, but also linguistically through discrete iconic and indexical signs.

Likewise, Chinese writing does not aim to account for the continuous and uninterrupted flow of meaningful (phonemic) sounds as does an alphabetic script. Rather, the Chinese script consists of discrete characters, where each is an integral whole arising from a complex interplay

4 See Kuriyama 1999, pp. 84, 10o, figs 13, 15, 16, 17; see also Ma 1983, p. 364, reproduced here in Fig. 2: 'Depiction of Chinese mai 脈').

$5 \quad$ Hsu 2010, pp. 351-7.

6 Peirce (1932) aligns himself with Western science, which does not contest the reality of fire but is doubtful of the reality of Chinese medical viscera, while the above analysis uses Peirce's indexical sign to highlight a relationship given as 'real' in Chinese medical texts. of visual form, sound and meaning. ${ }^{7}$ Chinese characters have been considered 'modular' in composition, given that their basic building blocks are recurrent. ${ }^{8}$ In most cases they are made up of an element that is indexical of a sound, and of another one, two or three elements derived from an iconic semblance. Accordingly, a Chinese character may be said to be an 'indexical-iconic' entity. This would allow us to see a continuity in iconographic style between the characters of the Chinese script and the above-mentioned Chinese pulse images.

In a similar vein, a posture in a bodily routine, like one of those in the Yijin jing, may be 'modular' in composition and visualised in the above iconographic style. Even if an iconic sign may appear static it can be indexical of temporality. The Chinese authors who made use of iconic-indexical signs obviously considered them suited to capturing the temporalities of the postures in martial arts routines, which were called shi 勢.

This chapter examines the visual rendering of shi 勢, which in translation is generally approximated as both a 'bodily posture' and a 'bodily movement', their efficaciousness and affordances. Evidently, the term shi is not easily translated, and François Jullien devoted an entire book to it, The Propensity of Things (original title: La Propension des choses. Pour une histoire de l'efficacité en Chine). ${ }^{9}$ His study has greatly enhanced our understanding of Late Imperial aesthetics in Chinese artistic expression. Furthermore, his insights put into perspective recent discussions of $t u$ 圖 (diagrams, maps, pictures) as used in science, technology and medicine texts. ${ }^{10}$

In what follows, I first introduce the primary source on which this study draws, namely the Yijin jing of 1624 as transmitted to us through the Neigong tushuo 內功圖 說 (Illustrated Exegeses on Inner Alchemy) of 1882, which outlines the shi (postures/movements) of popular forms of the martial arts and so-called 'inner alchemy'. Then, we will engage with Jullien's inspiring discussion of the term shi, before examining the specific shi (postures and/or movements) of the Yijin jing. Finally, we will turn to the opening and closing shi of the Yijinjing bodily routines, and the conceptions of time that their visualisaiton in the $t u$ diagrams might imply. Based on these observations I will formulate an argument that may be of text-critical interest and propose to consider the Yijinjing as a composite assemblage, comprising distinctively Daoist routines at its core,

\footnotetext{
$7 \quad$ Karlgren 1923.

8 Ledderose 2000.

9 Jullien 1995.

$10 \quad$ See Bray et al. 2007.
} 
rather than being a syncretic amalgamate within which core elements have been transformed beyond recognition.

\section{The Yijin Jing 易筋經 (Canon for Supple Sinews) of 1624}

The Yijin jing is thought to have been compiled in the early 17 th century and is, according to Meir Shahar, an epitome of late Ming syncretism. ${ }^{11}$ It is attributed to a certain Zongheng 宗衡 from Mount Tiantai in Zhejiang, whose sobriquet was Zining daoren 訾凝道人, 'Purple Coagulation Man of the Way'. A daoren would usually be a Daoist priest but at the time, the term may also have designated a Buddhist monk. Shahar is careful to point out furthermore that the word ning in the sobriquet Zining daoren can refer to an alchemical elixir, not least as the bodily techniques he discussed were at the time likened to alchemical processes. Accordingly, the compiler of the Yijin jing might also be rendered as the 'Purple Elixir Daoist'.

Shahar notes that the Yijin jing exercises were not originally performed within the Buddhist Shaolin temple. Although he refers to them as Weituo's 韋䭾 exercises, and Weituo (Skanda) was a popular tutelary divinity in Chinese Buddhism, Shahar notes that these exercises derived at least in part from Daoist gymnastics of daoyin 導引 'guiding and pulling'. He deduces this from their naming, as for instance 'guarding the centre' (shou zhong 守中). Or, as in the case of so-called 'energy absorption' from the sun and moon, he notes that it was already being practised in Daoist circles in medieval times.

Shahar also notes that the Yijin jing was endowed with two prefaces that linked it to the martial arts. One preface, which claimed that the manual originated from the famous Boddhidharma (Damo 達摩 in Chinese) was signed by the Tang dynasty general Li Jing 李靖; the other preface was signed by the Song dynasty general Niu Gao 牛臬. On the basis of anachronisms identified in these two prefaces, scholars of the Qing already dismissed both as forgeries. ${ }^{12}$ How did these prefaces become associated with the Yijin jing text? Shahar mentions a Daoist tradition from medieval times that attributed daoyin gymnastics to Boddhidharma. Furthermore, the Shaolin monks who eventually incorporated the Yijin jing exercises into their martial routines ${ }^{13}$ certainly would have been keen to align themselves with Buddhist predecessors. We note that at one point in history these routines were transmitted in

\footnotetext{
11 Shahar 2008, pp. 160-5.

12 Ibid.

13 Shahar 2008, pp. 171-2.
}

Buddhist circles. And although scholars of the Ming often point out that it makes little sense to try to disentangle Buddhist from Daoist practices in a syncretic milieu, the findings regarding the iconography of time that are presented in this study suggest that differences both existed and persisted.

\section{The Neigong Tushuo 內功圖說 (Illustrated Exegeses on Inner Alchemy) of 1882}

The textual history of the Yijin jing is complicated..$^{14}$ The version which is currently the most popular in the People's Republic of China is the one found in Wang Zuyuan's王 祖源 Neigong tushuo of 1882. It was reprinted in facsimile in 1956. The meditation routines discussed there are given in 12 full-page depictions of shi on pp. 47-58. Each page depicts, within a rectangular frame, a human figure assuming a certain posture (shi), usually enclosed to the left and right by one or two lines of text, and headed on the top by text that gives the posture's name. Although the illustrations are prints published as tushuo (exegesis by means of illustration), it seems farfetched to aim to categorise these images according to a typology which distinguishes between $t u$ as 'symbolic mediation' and $t u$ as 'technical illustration', as does Bray. ${ }^{15}$ We will see that these tushuo of inner alchemy also fulfil certain aesthetic criteria of hua 畫-ink brush paintings.

In Bray's typology, which is formulated in full awareness of it being an entirely 'etic' definition, Wang Zuyuan's illustrations would be secular and didactic, and thus would fall into her second type of $t u$ (rather than being endowed with ritual and/or symbolic power, as is her first type). However, although such a typology, which aims to separate the 'symbolic' from the 'technical', might appear useful, it carries the danger of projecting deeply engrained biases of Western scholarship into Chinese practices. Bray points here to a 'practical logic' that can be surprisingly constant across different times and cultures (other scholars speak of 'common grounds' or of the 'common sensical'). However, it is important to keep in mind the very fundamental social anthropological insight that human perception, practice and technology cannot be entirely divorced from meaning-making processes.

Bray's survey of $t u$ starts by noting that $t u$ in pre-dynastic China were thought to 'order' and to 'position in space'. She refers to Wolfgang Behr, who noted that in the

\footnotetext{
14 Shahar 2008, pp. 203-4, lists six editions, among which only the most recent is dated, being signed by a Zining daoren in 1624 .

15 Bray 2007, p. 34
} 
ancient China of the Zhou, a habit developed of writing a wei $\square$ enclosure around some words denoting places or place names. Among those was the character $b i$ 啚, known to have occurred on oracle inscriptions, not least as the predecessor of $b i$ 鄙 meaning 'border town, military base, garrison, fortress'. ${ }^{16}$ In this way, $b i$ surrounded by wei transmuted into the character $t u$ 圖 as known today. However, Behr also notes that already in Zhou China tu could be written with a heart determiner (xin 心) and remarks in that context - which concerns the making of a necropolis - that $t u$ functioned both as a plan for action and as a ritual object. ${ }^{17}$ Behr thereby made use of Bray's typology but only to show that it does not apply to $t u$ in pre-dynastic China.

The human figures depicted in the Yijin jing are given in a rectangular frame, seemingly following this early habit of framing a position in space with a wei enclosure. Since the figures adopting different postures are framed, one might be inclined to interpret them as constitutive of a $t u$. However, the text refers to them as shi. As can be gleaned from their names, they are rife with cosmogonic implications, where 'cosmogonic' means that they have the power to (re-)create the cosmos.

Jullien says shi relates to the efficacy of one's position. His discussion of shi, as 'potential born of disposition', starts with its implications in the military and in politics and ends with its importance in divination and the historical imagination. ${ }^{18}$ Here one senses some affinity between a shi and a $t u$. Both are action- and practice-oriented. Yet however action-oriented a strategic position shi may appear to be, Jullien insists on its dynamism, which goes beyond the here and now, on the tension and suspension that it evokes, and on how the physical and visible aspects of shi are oriented towards and defined by aspects that are invisible, hidden or not yet materialised. Jullien stresses that shi was the term par excellence that Chinese literati used for aesthetic valuation, particularly that of the brush stroke and of the arts performed with the brush: calligraphy, painting and literary composition.

In this context we note that the human figures in the Yijin jing were initially drawn with an ink brush; and in line with the aesthetic requirements of ink brush paintings (hua), each illustration contains a composite of figurative expression (a semi-clothed human body) and text (in plain Chinese characters). As we already know, and as Jullien tells us again, in hua paintings, figure and figurative speech together are meant to evoke an emotion.

\footnotetext{
16 Behr 2007, pp. 114-15.

17 Ibid., pp. 117-19.

18 Jullien 1995.
}

In Wang Zuyuan's Neigong tushuo we see martial arts 'postures' or 'movements', shi, but to view them merely as technical $t u$, i.e. as representations for practical instruction, might miss the point. 'A shi starts out as a painterly technique; but it also and inevitably provokes emotion.' ${ }^{19}$ Evidently, the aesthetic creativity of a shi transcends the representational and aims to convey the power, efficaciousness and/or propensity of the configuration that it depicts. So although the compilation in which these shi of the Yijin jing are recorded called itself a tushuo, and even though it may have been compiled primarily for technical and didactic reasons, the reduction of these shi to so-called 'technical' $t u$ merely reinforces a Western bias. Most importantly, it misses out on their efficacious aesthetics, which is ultimately cosmogonic.

\section{What is a Shi and What is Shi?}

In English, a 'posture' or 'movement' is a shi and the posture's efficaciousness is shi. However, in Chinese, one and the same term applies. In the contemporary martial arts there are three basic units for bodily routines: ${ }^{20}$ the shi is generally considered the most basic unit, and is often stationary, like a 'posture'; the zhao 招 is a sequence of movements ending with a strike; and the tao 套, traditionally also called $l u$ 路, comprises long sequences of movements that form a complete exercise.

Jullien discusses the connotations of shi in the martial arts in a chapter called 'Categories of efficacious dispositions. ${ }^{21} \mathrm{He}$ refers to body routines, like those of Taiji quan 太極拳 or the Yijin jing, as 'technical lists'. 'These lists constitute an altogether new type of literature for us,' he comments, saying that 'such technological codification has not been the object of much study.'.22 I could not agree more with the latter statement but take issue with his rendering as lists' what to practitioners are meaningful zhao or tao. The bodily routines presented in what follows have clearly identifiable openings and closings. Furthermore, the sequencing of the shi appears to be rife with meaning.. ${ }^{23}$

$S h i$ is a 'practical efficacy', Jullien notes in his discussion of shi in warfare, and this applies also to shi in the martial arts. Furthermore, Jullien remarks, these 'physical exercises' have a 'full cosmic dimension'. In this sense, they are cosmogonic: 'When I push in this manner with my hands,

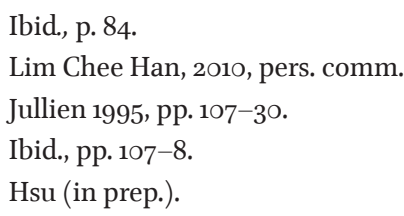


I am pushing against the Invisible in its entirety'. ${ }^{24}$ When Jullien says 'any initiate of Chinese fist boxing learns to master a whole succession of fragments of movements that cannot be equated on a one-to-one basis with the various shi, ${ }^{25}$ we are reminded that the zhao and the shi, the tao $l u$, and their components, form what Lederrose would consider parts of a 'modular pattern'. ${ }^{26}$

Although shi relates to the concrete configuration of a situation, i.e. to practical and technical matters, it is a term with aesthetic implications, which evokes awareness of the invisible and spiritual, of cosmic rhythms and potentialities and of the depth and power of human emotion. Shi describes 'a propensity' that 'emanates from its constitution' ('just as a spherical body tends to roll and a cubic one remains still'), ${ }^{27}$ a shi collapses the present tense with the future. With this latter example, Jullien implicitly likens shi to the concept of 'affordance', which in the early 2 oth century phenomenologist philosophers and psychologists developed (and which Science and Technology Studies have further elaborated). The shi does not imply a mechanical functionalism or an Aristotelian teleology; rather it has the potential to give rise to life through the actualisation of internal energy and denotes in its current configuration the effect that it will produce in the future. ${ }^{28}$ This sort of temporality and causation, as a suspended tension of present immobility, imbued with triggers that effect future movement, is central to the notion of shi.

As enlightening as Jullien's discussion of shi is in general terms, his comments on the shi of Taiji quan and their relation to time seem to rely unreflectingly on his modern understanding of time, when he says, 'it is not possible to distinguish between one individual "position" and the movement that both stems from it and leads into it'. ${ }^{29}$ Here, Jullien is clearly imposing his understanding of time as a continuous flow on the temporality implied by the bodily routines in Taiji quan. However, just as the calligrapher writes discrete yet dynamically connected units of Chinese characters when expressing the flow of his thoughts, so too the martial artist adopts a sequence of 'postures' or 'movements' that involve both the dynamism of movement and the tension of stillness. Those shi enact both the present and the future, where the meticulous attention to minute differences in bodily posture is rewarded with the overwhelming emotional, if not spiritual,

\footnotetext{
24 Jullien 1995, p. 115.

25 Ibid., p. 114.

26 Ledderose 2000.

27 Jullien 1995, p. 85 .

28 Ibid., p. 78.

29 Ibid., p. 113
}

effects that these technicalities can strategically evoke. As documented by Judith Farquhar and Zhang Qicheng, feelings of joyfulness and peacefulness arise spontaneously on those occasions. ${ }^{30}$

Shi encompasses both form and content. Although Jullien fails to see that a similar collapse of temporality applies to shi in the martial arts, he is explicit about this with regard to the literary arts:

The 'form' through which the literary shi is realised is that of a particular configuration which itself operates spontaneously to create an effect. Thus, what we customarily translate as 'form' in Chinese texts of literary criticism is not the opposite of 'content' but the end of a process of 'actualization', shi being the potentiality characterizing the actualization. ${ }^{31}$

Applied to the martial arts, a shi is the form, the posture and the movement; shi is the contents, the tension, the power and the posture's efficaciousness, which spontaneously evokes feelings and emotions, and ultimately is cosmogonic (in that it has the potency to recreate the cosmos). In the Chinese language, as already said, this distinction between a shi and shi is not made.

\section{Practising the Yijin Jing}

During ethnographic fieldwork in 1988-9 I encountered a practitioner of the Yijin jing in a popular neighbourhood of Kunming city on a street known as that of the poor (pinmin jie 貧民街). At the time this practitioner, who readily agreed to teach me what he called Qigong 氣功 (merits achieved through breathing [techniques]), did not stress that the movements he taught me were those of the Yijinjing, although he did name some of them in order to change my performance of the movement in question through imagination (the imagination of enacting a wild animal, for instance).

In 1988-9 I did not write down the names of the movements, as I was told them in the darkness of a park and I only partially understood them. Nor did I dare to ask Master Qiu (a pseudonym) to write them down for me systematically, as he treated his teaching as secret knowledge. Although I soon became aware that degrees of secrecy were negotiable, ${ }^{32}$ I hesitated to press him to give me factual information that might have unnecessarily endangered him in the then prevailing political climate. However, while writing up my doctorate, I came across

\footnotetext{
$30 \quad$ Farquhar and Zhang 2012.

$31 \quad$ Jullien 1995, p. 88.

$32 \quad$ Hsu 1999, p. 52.
} 
Wang Zuyuan's facsimile edition in the open stacks of the Needham Research Institute, Cambridge. ${ }^{33}$ I still remember vividly today how forcefully I was struck by the images of movements seemingly identical to the ones I had learnt. They captured them so well - in their very essence, one would like to say (if being 'essentialist' were not decried as the worst possible crime a contemporary social anthropologist can commit). I was strangely touched and somewhat stirred when I saw a guarded secret unfold in front of me, in black and white, as I turned the pages. However, there were 12 pictures of movements whereas I had learnt 10, and some seemed different altogether. Furthermore, their sequencing was not as I had learnt it. ${ }^{34}$ I did not further pursue this issue then, especially as I found no secondary literature on it.

Twenty-one years later, in 2009, Qigong master Qiu was one of the few in the People's Republic of China who continued to do daily Qigong meditation in his privately owned house in another popular neighbourhood. The Qigong fever of the late 8 os had long abated. When I came to visit Qiu and stayed with his family, one of the several other disciples he had taught after me happened to drop by for a visit. In this context, I reconfirmed with Qiu, as I had already done on a previous occasion in 2005, that he had taught me the Yijinjing. Yes, indeed. This time I asked Qiu the names of the 10 movements and his disciple wrote them down. ${ }^{35}$ They turned out to be very similar to the names in Wang Zuyuan's edition of 1882, which are listed below (Qiu's sequencing is given in capital letters):

1. (A) Weituo offers his vajra club, first posture (Weituo xian gan di yi shi 韋䭾獻杵第一勢)

2. (A) Weituo offers his vajra club, second posture (Weituo xian gan di er shi 韋䭾獻杵第二勢)

3. (A) Weituo offers his vajra club, third posture (Weituo xian gan di san shi 韋䭾獻杵第三勢)

4. (C) Pluck the stars and reverse the dipper posture (zhaixing huan dou shi摘星換斗勢)

5. (F) Turn around nine oxen by pulling their tail posture (dao zhuai jiu niu wei shi 倒拽九牛尾勢)

6. (B) Put forth the claws and spread the wings posture (chu zhua liang chi shi 出爪亮翅勢)

7. (E) Nine ghosts draw the horse sabre posture (jiu gui ba ma dao shi 九鬼拔馬刀勢)

8. (D) Three plates fall to the ground posture (san pan luo di shi 三盤落地勢)

9. (G) The blue-green dragon surveys its claws (qing long tan zhua shi 青龍探爪勢)
10. $(\mathrm{H})$ The crouching tiger pounces on its prey (wo hu pu shi shi 臥虎撲食勢)

11. (J) Make a bow posture (da gong shi 打躬勢)

12. (J) Wagging the tail posture (diao wei shi 工尾勢)

What I call in English a movement or posture, I was taught during a single session on one evening. It was clearly a conceptual entity for my teacher as he spaced my teaching of each movement accordingly, and if prompted, would give me a name for each. A new movement was typically initiated by changing the position of both feet. As Despeux has noted, the body is always slightly off balance, thereby containing within each shi the tension leading into the next. ${ }^{36}$ One remains rooted to the ground, while stretching, bending and twisting one's arms, legs and torso according to a clearly prescribed routine, repeating each movement, in Qiu's case, seven times. Qiu was not verbal about how to perform such a posture or movement but Chinese scholarship calls it a shi.

In this context the affect that the Neigong tushuo generated is worth noting. As already mentioned, I instantly recognised the body routines I myself had enacted when seeing the images. I also remember that one of my teachers reacted to them with endearment, in a noticeable way. I would not have mentioned this auto-ethnographic detail, if C.S. Peirce had not made a comment precisely on the impact iconic and indexical signs have on one's mood. ${ }^{37}$ Peirce says of the symbol (the 'symbolic sign'), which, like the linguistic 'sign' defined by Ferdinand de Saussure, ${ }^{38}$ is based on convention, that it is assertive and declarative. It makes a statement in the indicative mood, so to speak. By contrast, Peirce claims, the iconic sign expresses a potentiality in the subjunctive mood and the indexical sign is exclamatory and calls for attention in the imperative mood. ${ }^{39}$ With regard to the effects it evoked, the Yijin jing images provided not so much a factual statement in the indicative mood and in terms of 'visual representations'. Rather, they combined the qualities of an iconic and an indexical sign; in an exclamatory way they reached into the emotional realms of the subjunctive and inchoate possibility. This is another reason why the Yijinjing's visual rendering of a shi, and implicitly of time, might best be conceived as 'iconic-indexical'.

36 Despeux 1975, 42-3; see also Jullien 1995, p. 133.

37 Peirce 1932, vol. ii, p. 169.

38 de Saussure 1916.

39 Summarised more comprehensively in Hsu 2010, p. $35^{2}$. 
In what follows I will describe my embodied experience of practising the opening and closing shi of the Yijin jing, and use this experience as a key to reading the images in Wang Zuyuan's Neigong tushuo. The methods of inquiry are thus most unusual. They involve, first, 'participant experience', ${ }^{40}$ which differs from 'participant observation' in that it requires the ethnographic fieldworker to gain the proficiency of a practitioner in the subject they study, or at least the ability to practise the subject or skill independently and without supervision. At the same time 'participant experience' requires one to stay committed to the ethnographic methods of note taking and diary writing and to the ethics of a participant observer, which is to adopt a humble attitude of learning and non-interference, as far as this is possible. Second, I engage in auto-ethnographic reflections.

Both of these methods - participant experience and auto-ethnography - are typically frowned upon, as they are interpreted as relying too much on so-called 'subjective' experience. However, if one adopts, as I do, a phenomenological orientation grounded in Merleau-Ponty's Phenomenology of Perception, which emphasises that processes of perception are 'physiognomic',11 one can redefine the field of inquiry that the empiricist sciences divide into one of active 'subjects' investigating passive 'objects' during a 'cognitive process' of 'decoding' 'reality'. The suggestion that perception, and with it the meaning-making process, is physiognomic highlights that perception is a process marked by indeterminacy, ${ }^{42}$ where a perceiver's surroundings gain their meanings and distinctiveness only through repeated and renewed interactions between what the empiricist sciences call the subject and the object. ${ }^{43}$ I justify taking recourse to the above methods through the inaccessibility of the topic studied. The martial arts and Qigong meditation are still today veiled in secrecy, although the Yijin jing has gained considerable publicity in the time since I first learnt it.

\section{The Opening and Closing Movements in the Yijin Jing}

Master Qiu's Yijin jing movements comprised a zhao or a tao of 10 shi, while Wang Zuyuan's had 12 images, and their sequencing differed. I go into a detailed analysis of

\footnotetext{
$40 \quad$ Hsu 1999, p. 15.

$41 \quad$ Merleau-Ponty 1962, p. 132

42 Ibid.

43 Well-explained by Morris 2012.
}

the different versions elsewhere ${ }^{44}$ and will limit myself here to discussing the opening and the closing movements.

The opening movement that I learnt from Qigong master Qiu resembled the closing movement in that both positions consisted of straightened legs, with feet kept parallel, touching each other at the ankle. It made one feel rooted to the ground, firm and symmetrical (the legs were not crossed, as in the first three postures in the Neigong tushuo (see Fig. 3)). One had no sense in this opening posture of being slightly off balance, except at one instance, that of standing on one's toes and stretching out both arms, while pushing with the outwardly turned palms upwards. This moment of being on tiptoe within the opening and closing shi was arguably a brief moment of going slightly off balance, but not in a lateral way, to either the left or right, as in the other movements. Rather, it felt to me as though I was supposed to assume a posture of absolute verticality to prop up the sky (the Neigong tushuo text does actually speak of propping up the 'gate of heaven', tianmen 天門, but Master Qiu provided no verbal comment). This opening movement that Qiu taught me consisted of the drawing out of a circle with arms stretched out to both sides. Over the many years of practising these bodily routines almost daily, I started to experience them as any anthropologist would do who suffers a déformation professionnelle: it felt as though the boundaries of a ritual space were hereby being demarcated.

In the closing movement one also draws a circle by folding one's hands into each other such that the palms face outward and by pushing them with stretched-out arms away from one's torso. First, one does so at shoulder height, then gradually bowing downward with the torso until the stretched out arms touch the ground with the outwardly facing palms while both legs are kept still and stretched. Thereupon, with interlocked palms facing the torso, one moves them along it upwards, passing by the abdomen, chest, neck, face, until one stands upright again. As one goes up onto one's toes to prop up the heavens, the palms are again interlocked and facing outwards, and stretched out upwards, before one starts drawing another circle in front of one's torso. It felt as though the closing circle was on an axis turned to go degrees in comparison to the opening movement.

An anthropologist finds it difficult to evade the impression that this final posture has a ritual implication. It seemed to delineate the ritual space in which the transformation of the person performing the meditation routine had taken place. Qiu put an additional end point to this Wang Zuyuan's sequence lacked Qiu's penultimate shi, (I), no. 9. 


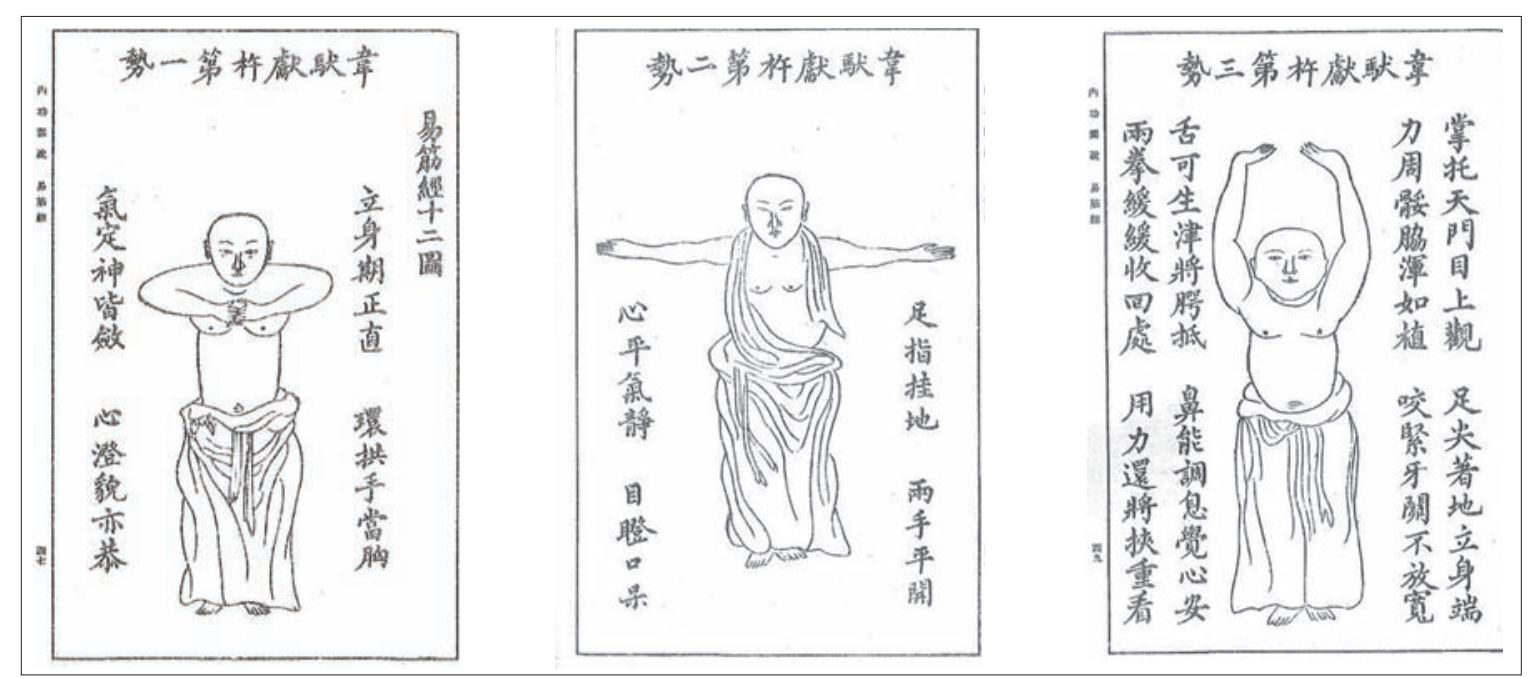

Figure 4.3 'Weituo offers the vajra' (Weituo xian gan 韋䭾獻杵). All three images bear the same title; accordingly, they depict one and the same shi. They provide 'freeze frames' of different stages of the movement that the practitioner enacts.

movement by thereafter resting his palms on his lower abdomen, the cinnabar field (dantian 丹田), into which Qi would return.

Equipped with this embodied understanding of the opening and closing movements, let us turn to Wang Zuyuan's Neigong tushuo. The first three images each give the title of the first shi, i.e. 'Weituo offers the Vajra', followed by the numbers one, two and three, (yi er san 二二三); hence those three images seem to account for one movement (see Fig. 3). So, rather than capturing the entirety of a shi in one iconic-indexical sign of psychological salience, the first three human figures seem to depict different stages of one movement, as though they were presenting 'freeze frames' along a linear trajectory of time. This is not instantly evident from the depictions on paper, but with the embodied knowledge of the bodily routine that the shi in question involves, one can appreciate them as 'snapshots' of different stages of drawing out a circle delimiting a ritual space, as is done in the first shi.

The 'cinematographic technique' 45 also presents itself as a possible iconographic style for interpreting the two last images: these two images both show a human figure seen from the same angle with feet positioned close to each other (see Fig. 4: 'Make a bow' and 'Wag the tail'). Hence one gets the impression that the sequence of these two images is used to depict one movement, the closing movement. The very last drawing has a title but no text and it looks like a humorously added endnote to this movement: one wags

45 Jullien 1995, p. 113 . one's tail, i.e. shakes one's bottom, as is still done today in another living tradition. ${ }^{46}$

By contrast, the seven shi in between account for time and temporality in an unmistakably iconic-indexical way, where the propensity for the future and its efficaciousness are contained in the configuration of the present (see Fig. 5: 'Pluck the stars and reverse the dipper'). In the sequence I learnt from Qiu, it is possible to discern a pattern of alternation of the broad postures (movements B, D, F) and the postures with crossed legs (movements $C, E, G$ ), which can be interpreted as enacting a pulsating Yin Yang pattern of a temporality understood in terms of a cosmogonic expansive Yang and contractive Yin. ${ }^{47}$ Wang Zuyuan's edition, however, sequences Qiu's shi in this order: A, C, F, B, E, D, G, $\mathrm{H}, \mathrm{J}$. It is of course possible that Wang Zuyuan's publication recorded the same pulsating Yin Yang sequence of postures as did Qiu and that it had to be read in a coded way. It is equally possible that such variations suggest a widespread predilection for playful recombination. Such cultivation of artistic expression that is playful evidently attended to both form and content, much as one does linguistically when formulating puns and rhymes.

Hsu and Lim 2016. Admittedly, the interpretation of the last two images as 'freeze frames' depicting one single shi, is not as robust as is that of the three 'freeze frames' depicting the opening shi.

47 Hsu (in prep.) further elaborates on this. 


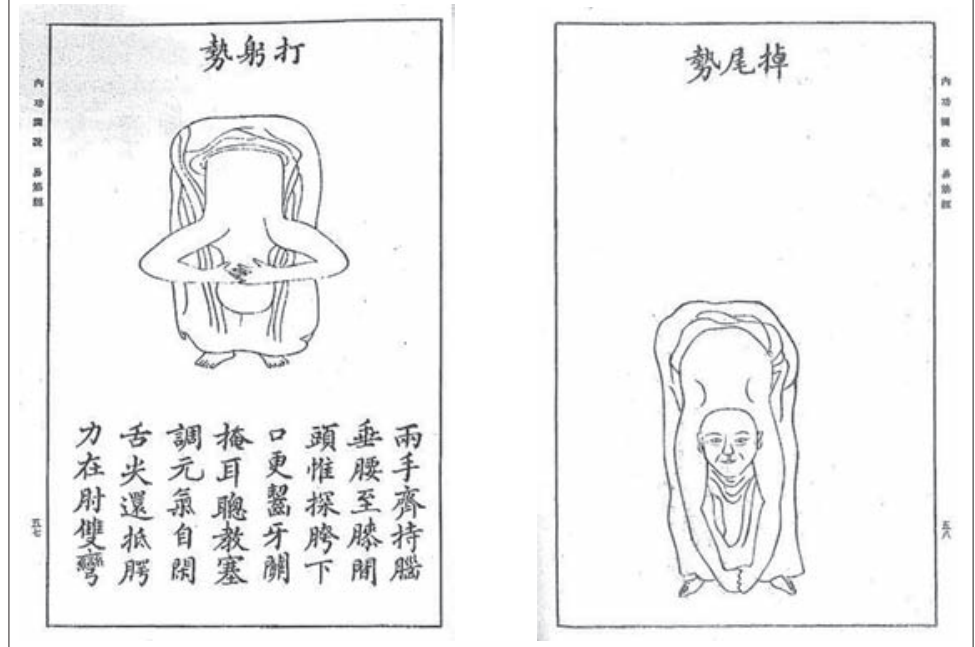

Figure 4.4 'Make a bow' (da gong 打躬) and 'Wag the tail' (diao wei 掉尾). Two 'freeze frames' of another single movement? Note that there is no text to the latter image.

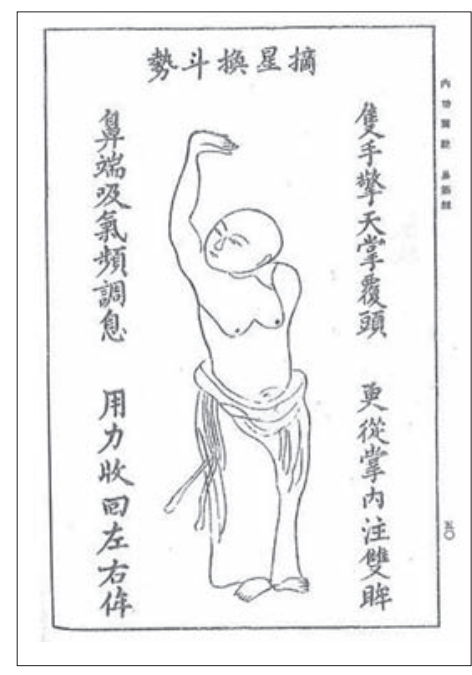

Figure 4.5 This one image depicts in an iconicindexical manner the shi called 'Pluck the stars and reverse the dipper' (zhai xing huan dou 摘星換斗)

\section{Text-Critical Considerations}

Our analysis of the iconography of time in the images of specific postures in martial arts routines does not stop short here and proceeds to make a text-critical argument. The above finding can be used as evidence that the current bodily routines of the Yijin jing are in fact a composite. In other words, the text in Wang Zuyuan's extant edition of the Yijinjing, and the illustrations accompanying it, seem to be made of at least two textual layers that can be distinguished from each other on the basis of their different iconographies of time. Accordingly, the three opening and the two closing shi would belong to a different textual layer from the seven shi in between.

We are here reminded that in The Propensity of Things Jullien endorses a somewhat elitist stance to texts (like that of the Yijin jing) as he considers them of 'late and secondary character' 48 and refers to them as 'lists'. He translates one such 'list' of 17 'Strategic dispositions in poetry' and, commenting on their 'heterogeneity' and 'incoherency', says: 'Could such a list really reflect little more than desultory, largely whimsical rumination?'49 Jullien herewith expresses the frustration that many a Western textual researcher experiences, which may arise from the oversight of, first, the deeper meanings of the playful in Chinese aesthetics and artistic expression, as hinted at above, and second, text-critical considerations. Since the

48 Jullien 1995, p. 281.

49 Ibid., p. 123. first concern is being dealt with elsewhere, ${ }^{50}$ I limit myself to text-critical considerations in the following discussion.

Throughout his works, Jullien shows little text-critical awareness. Notably, he says of these lists' that they date to the Tang dynasty, and he even speculates why this might have been so. ${ }^{51}$ One of the two prefaces to the Yijin jing would indeed make it appear to be a Tang dynasty text. However, both prefaces of the Yijin jing that supposedly dated to the Tang and Song dynasties have been identified as 'forgeries'. Accordingly, one wonders whether the prefaces to this literature of 'lists' of 'technological codification' were meant to imbue it with the weight of a millennium-long tradition. In this context, it is noteworthy that the primary source-material Jullien relies on throughout his monograph is largely from Ming and Qing China. In particular, when he talks about the importance of shi in Song paintings ${ }^{52}$ and Chinese philosophies about historical change, ${ }^{53}$ he actually draws amply on Late Imperial source-materials. ${ }^{54}$ This could be taken as a hint that the notion of shi starts to gain centre stage in the imagination

\footnotetext{
50 Hsu and Lim 2016, Hsu (in prep.).

$51 \quad$ Jullien 1995, p. 108.

$5^{2} \quad$ Ibid., ch. 5, pp. 98-105.

53 Ibid., pt iii.

54 See two works of Wang Fuzhi 王夫之 (1619-92) mentioned on p. 291, and note figs 1-5 and 10-11, on pp. 162-70, from the Jieziyuan huazhuan 芥子園畫傳 (Manual of the Mustard Seed Garden). It is puzzling that although Jullien (1995) begins with the discussion of shi as central to Sunzi's 孫子 militaristic strategising and the legalistic philosophical stance in the Han Fei zi $i$ 韓非子 of pre-Imperial China, the Hanyu da zidian 漢語大詞典 notes that the character shi does not exist in pre-Imperial texts.
} 
of Chinese literati only by the 17 th century. It happens, as Jullien convincingly underlines, in an all-encompassing way, thoroughly affecting philosophical, artistic and technologically-oriented literatures.

Furthermore, as established above, the visual rendering of the opening and closing shi in Wang Zuyuan's Neigong tushuo relates to time as a linear trajectory, in contrast to the seven shi at the core of the Yijin jing bodily routines, which appear to relate to time in an iconic-indexical way. Incidentally, the depiction of the flow of time along a linear trajectory is also implied by the way in which Tibetan medical doctors (who were Buddhist) depicted the pulse on the thanka of the 17th century Blue Beryl, as mentioned in the beginning of this chapter (Fig. 1). The allusion to a linear flow of time when depicting Tibetan medical pulse movements contrasts with the iconic-indexical rendering of the Chinese medical pulse/mai (Fig. 2).

In addition, the bodily movements in both the opening and the closing shi of the Yijin jing, much like the Tibetan Buddhist medical pulse movements, are marked by verticality: the practitioner stands straight, symmetrically grounded, with parallel feet, ankles touching each other (in both cases, the knees are not bent and there is no sense of being slightly off balance, as is characteristic of the Chinese martial arts).

Finally, the opening movement refers to a Buddhist figure, Weituo.

What can we deduce from this observation? Might there have been a distinctively Buddhist comprehension of time that spanned across 17 th century Tibet and 17th-19th century China? Might this Buddhist comprehension of time as a flow have led to its depiction along a linear trajectory? Herewith we find ourselves in the midst of text-critical scholarship and its concern with textual layering. We have not investigated rhyme and rhythm, graphs and writing utensils, but scrutinised the iconography of shi as a textual genre. Based on the different iconographic styles in which the images in Wang Zuyuan's edition refer to time, we can hypothesise that the opening and closing shi are of a different cultural provenance from most of those at the core of the Yijin jing sequence.

If this were the case, it instantly raises the question: why should a basically Daoist stock of daoyin practices surround itself with opening and closing shi drawn in an iconography of linear time? Might Zining daoren in fact have been a Daoist who compiled a routine of eight shi and might, only later, one of his followers have decided to add the opening and closing routines? ${ }^{55}$ Might these two have

The Singaporean version of the Yijin jing, discussed in Hsu and Lim 2016, consists of eight shi. been of Buddhist provenance? If that were the case, the Yijin jing would basically be a Daoist routine. It might even have had a closing movement of its own, as Master Qiu's penultimate shi felt very much like a closing movement too (see fn. 44), but that shi does not appear to be given in Wang Zuyuan's version of the Yijin jing sequence of postures.

If the Yijin jing is Daoist at its core but in Wang Zuyuan's version packaged as Buddhist, what are the political and social historical events in Late Imperial China that could provide a motivation for explaining this? Shahar reminds of the pre-eminent position of the Shaolin temple and notes that martial arts practised on its grounds in the 19th century were thoroughly Daoist. ${ }^{56}$ How and why did this happen?

Here an episode from another fieldwork site may prove useful. In autumn 2009, while doing three months of ethnographic fieldwork in my ancestral village (Hsuvillage in Huizhou, Anhui province), in a moment when our conversation had died away into silence after it had provoked a non-verbalised but palpable sadness over the destruction effected by the Red Guards (some of them my dear hosts), a villager had his teenage son bring me a cookbook out of a backroom of the remains of his large Ming-dynasty house. He was proud to show me that he had saved this book from the flames, and with it a tiny bit of Chinese culture and cuisine. However, both book covers, i.e. the title page and the end page, had been discarded. I did not need to ask why. It was obvious. They carried politically relevant information.

In a similar vein, the Yijinjing may at its core consist of Daoist practices that are packaged as Buddhist: it may not be a coincidence that Wang Zuyuan's edition depicts the opening and closing movements along a linear timeline, and hence according to a different iconography of time from the seven core movements. Furthermore, it is worth noting that just in the opening and closing movements the practitioner's posture is marked by verticality. Finally, we are reminded that the Yijin jing's prefaces alluded to a Buddhist provenance.

Here I defer to the social historian of Late Imperial China, yet wish to add one final note on method relevant to this book project on the visualisation of Chinese medical practices. As the above has shown, in order to interpret the visual depiction of postures, gestures and movements of the martial arts and other routinised bodily practices in historical texts and other written documents, a practical and embodied understanding of them is crucial.

$56 \quad$ Shahar 2008. 


\section{Bibliography}

\section{Primary Sources}

Wang Zuyuan 王祖源 [1882] 1956: Neigong tushuo 內功圖說 (Illustrated Exegeses on Inner Alchemy), Beijing: Renmin weisheng chubanshe, $47-58$.

Wang Gai 王概, Wang Shi 王萻, Wang Nie 王香 (vol. i, 1679; vols ii and iii, 1701) 196o, Jiezi yuan huazhuan 芥子園畫傳 (Manual of the Mustard Seed Garden), Beijing: Renmin meishu chubanshe.

\section{Secondary Sources}

Behr, W. 2007, 'Placed into the right position: etymological notes on $t u$ 圖 and congeners', in Bray, Dorofeeva-Lichtmann and Métailié (eds), 109-36.

Bray, F. 2007, 'Introduction: the powers of $t u^{\prime}$ ' in Bray, DorofeevaLichtmann and Métailié (eds), 1-78.

F. Bray, V. Dorofeeva-Lichtmann and G. Métailié (eds) 2007, Graphics and Text in the Production of Technical Knowledge in China: The Warp and the Weft, Leiden: Brill.

Despeux, C. 1975, T'ai-k'ik'uan:technique de longue vie, technique de combat, Paris: Collège de France, Institut des Hautes Etudes Chinoises.

Farquhar, J. and Zhang Qicheng 2012, Ten Thousand Things: Nurturing Life in Contemporary Beijing, Cambridge, MA: MIT Press.

Hsu, E. 1992, 'The Transmission of Knowledge, Texts and Treatment in Chinese medicine', PHD diss. in Social Anthropology, University of Cambridge.

1999, The Transmission of Chinese Medicine, Cambridge: CuP. 2010, Pulse Diagnosis in Early Chinese Medicine: the Telling Touch, Cambridge: cuP.

(in prep.), 'History in the Body: the Yijinjing 易筋經 (Canon for Supple Sinews)'.
Hsu, E. and Chee Han Lim 2016, 'Enskilment into the Environment: the Yijinjing 易筋經 Worlds of jin 筋 and q $i$ 氣'. Berlin: MPIWG (Max Planck Institut Wissenschaftsgeschichte), Preprint Series.

Jullien, F. (tr. J. Lloyd) 1995, The Propensity of Things: Toward a History of Efficacy in China, , New York: Zone Books.

Karlgren, B. 1923, Sound \& Symbol in Chinese, Oxford: Clarendon.

Kohn, L. 2008, Chinese Healing Exercises: the Tradition of Daoyin, Honolulu: University of Hawai'i Press.

Kuriyama, S. 1999, The Expressiveness of the Body, and the Divergence of Greek and Chinese Medicine, New York: Zone Books.

Lederrose, L. 2000, Ten Thousand Things: Module and Mass Production in Chinese Art, Princeton: Princeton University Press; Leiden: Brill.

Lo, V. 2007, 'Imagining Practice: Sense and Sensuality in Early Chinese Medical Illustration', in Bray, Dorofeeva-Lichtmann and Métailié (eds), 383-423.

Ma Kanwen 1983, 'Diagnosis by Pulse Feeling in Chinese Traditional Medicine', in The Institute of the Natural History of Sciences, Chinese Academy of Sciences (eds): Ancient China's Technology and Science, Beijing: Foreign Languages Press, 358-68.

Merleau-Ponty, M.M. [1945] (tr. C. Smith), 1962, The Phenomenology of Perception, London: Routledge and Kegan Paul.

Morris, K. 2012, Starting with Merleau-Ponty. London: Continuum.

Parfionovitch, Y., D. Giurme and F. Meyer (eds) 1992, Tibetan Medical Paintings: Illustrations to the 'Blue Beryl' Treatise of Sangs Rgyas Rgya mtsho (1653-1705), London: Serindia.

Peirce, C.S. (C. Hartshorne and P. Weiss eds) 1932, Collected Papers, vols. i-vi, Cambridge, MA: Harvard University Press.

de Saussure, F. [1916] 1949, Cours de linguistique générale, published by C. Bally, and A. Sechehaye, in collaboration with A. Riedlinger, Paris: Payot.

Shahar, M. 2008, The Shaolin Monastery: History, Religion, and the Chinese Martial Arts, Honolulu: University of Hawai'i Press. 